\title{
Current Use of Depression Rating Scales in Mental Health Setting
}

\author{
Eun Jeong Lee ${ }^{1}$, Jung Bum Kim¹, Im Hee Shin², Kyung Hee Lim³, Sang Hee Lee, Gyung Ah Cho \\ Hyung Mo Sung ${ }^{6}$, Sung Won Jung ${ }^{1}$, Mark Zmimmerman ${ }^{7}$ and Yanghyun Lee ${ }^{8 凶}$ \\ ${ }^{1}$ Department of Psychiatry, Dongsan Medical Center, Keimyung University School of Medicine, Daegu, Korea \\ ${ }^{2}$ Department of Medical Statistics, Catholic University of Daegu, School of Medicine, Daegu, Korea \\ ${ }^{3}$ Regional Military Manpower Office, Daegu, Korea \\ ${ }^{4}$ Department of Psychiatry, Seodaegu Daedong Hospital, Daegu, Korea \\ ${ }^{5}$ Sanullim Hospital, Daegu, Korea \\ ${ }^{6}$ Department of Psychiatry, CHA Gumi Medical Center, CHA University, Gumi, Korea \\ ${ }^{7}$ Department of Psychiatry and Human Behavior, Brown Medical School, Providence, RI, USA \\ ${ }^{8}$ Department of Psychiatry, MunGyeong Jeil General Hospital, Mungyeong, Korea
}

Objective This study was to investigate the current use of depression rating scales by psychiatrists and clinical psychologists in Korea. Methods The questionnaires from many psychiatrists and clinical psychologists were included in the analysis. The questionnaire was composed of items about examining the percentage of patients clinically using depression rating scales, reasons for not use of them, the degree of satisfaction, the perceived agreement rate between the result of depression rating scales and doctor's clinical interview in the evaluation of patients with depressive symptoms. Data were analyzed by $\chi^{2}$ and independent $t$-test.

Results The clinical use of depression rating scales was more frequent in the psychologists than in the psychiatrists. The purposes for using depression rating scales were assessed into six areas, there was no significant difference in between two groups, and both groups pointed out their purpose as rating of severity and screening. The reasons for not using scales were that their interview may be sufficient for diagnosis and assessment of depressive patients and they are not familiar with the use of depression rating scales. The psychiatrists usually prefer the Beck Depression Inventory (BDI), Hamilton Depression Rating Scale and Symptom Checklist 90-Revision (SCL-90-R) in order of frequency, and the clinical psychologists are more likely to use the BDI, Minnesota Multiphasic Personality Inventory and SCL-90-R. Overall rate of satisfaction in the use of the scales was $67.29 \pm 14.45 \%$ and overall perceived agreement rate was $70.89 \pm 16.45 \%$.

Conclusion Currently used depression rating scales at the clinical practice were not various. Therefore, to heighten clinicians' utility of these depression rating scales measures, either educational efforts or advertisements, or both, will be necessary to spread them wildly.

Psychiatry Investig 2010;7:170-176

Key Words Depression Rating Scales, Purpose of use, Agreement, Satisfaction, Kinds of use.

\section{INTRODUCTION}

Depression is a common psychiatric problem, so one out of ten experiences it one or more times for a whole life and the probability of having it for a whole life reaches to $30 \% .{ }^{1}$ However, it is also a very serious disease because $10-15 \%$ of patients with depression can show fatal outcomes such as suicide. Ac-

Received: April 13, 2010 Revised: July 8, 2010

Accepted: July 27, 2010 Available online: August 13, 2010

$\triangle$ Correspondence: Yanghyun Lee, MD, PhD

Department of Psychiatry, MunGyeong Jeil General Hospital, 188 Mojeondong, Mungyeong 745-882, Korea

Tel: +82-54-550-7977, Fax: +82-54-555-4034

E-mail: yanghyun.lee@gmail.com

(a) This is an Open Access article distributed under the terms of the Creative Commons Attribution Non-Commercial License (http://creativecommons.org/licenses/by$\mathrm{nc} / 3.0$ ) which permits unrestricted non-commercial use, distribution, and reproduction in any medium, provided the original work is properly cited. cording to 'Global Burden of Disease Study' funded by World Health Organization, depression ranked the fourth among total diseases by accounting for 3.7\% of the total disabilityadjusted life-years (DALY) in 1990 and it was expected to become the second by recording $5.7 \%$ of the total DALY in $2020 .^{2}$ According to study of cross-national epidemiology of major depression, the lifetime prevalence for major depression vary widely across countries, ranging from 1.5 percent in Taiwan and 2.9 percent in Korea to 19.0 percent in Beirut. In every country, the rates of major depression were higher for women than men. ${ }^{3}$ An epidemiological survey conducted 2009 in Korea also that lifetime prevalence of major depressive disorders was $5.6 \%$ and lifetime prevalence according to gender showed higher for women than men as 3.6\% in males and 7.6\% in females. ${ }^{4}$ However, cultural differences or different risk 
factors affect the expression of the disorder ${ }^{3}$ and the definition of depression or measures for assessing a prevalence of depression is different as studies. ${ }^{4,5}$ When if existing studies of prevalence considered above factors, the total prevalence of depression is considered to be higher in clinical practice. ${ }^{5}$ Therefore, there has been increasing interest to the depression rating scales for objective measure and easy use as well as for early diagnosis, differential diagnosis, and assessment of severity of depressive disorders. ${ }^{6-8}$

Rating scales are a research tool that can systematically verify the hypotheses of clinical judgment, decision making, and psychopathology, as well as a measurement tool that transforms the implicit and explicit observation into quantitative data. ${ }^{8}$ So far there are 16 clinician-rated and self-rated inventories for depression standardized in Korea, such as Beck Depression Inventory (BDI), ${ }^{9}$ BDI-II, ${ }^{10}$ Zung's Self-Rating Depression Scale, ${ }^{9-11}$ Minnesota Multiphasic Personality Inventory (MMPI) ${ }^{12}$ Symptom Checklist 90-Revision (SCL-90-R), ${ }^{13} \mathrm{~Pa}-$ tient Health Questionnaire (PHQ-9), ${ }^{14}$ Geriatric Depression Scale ${ }^{15,16}$ and Children Depression Inventory. ${ }^{17,18}$ Most of them, however, were translated and standardized with the original scales developed in other countries. The only depression rating scale developed in Korea is 'Korean Depression Scale' of Lee and Rhee. ${ }^{19}$ Purposes of using these scales vary from determining severity of symptoms to differentiating various diagnoses of mental disorders and to observing the degree of improvement after treatments. ${ }^{10}$ The types of scales are different according to what is measured.

To determine the impact of treatment in mental health clinical setting, it is necessary to evaluate the treatment outcome. While governmental policy statements on mental health practice over the past decade have emphasized individual patient's outcome, little is known about the actual use of standardized outcome measures by clinicians. ${ }^{20}$ Current domestic situation is emphasized to use objective measures such as BDI, Rating Scale for Depression (HRDS) which evaluate treatment outcome and severity of depressive symptoms, and so it is a global trend for clinicians to encourage a use of depression rating scales. ${ }^{10,20}$ Gilbody et al. ${ }^{22}$ surveyed 340 psychiatrists in the United Kingdom regarding their use of outcome measures. Only $10.5 \%$ and $11.2 \%$ of the psychiatrists routinely used standardized measures to assess severity and outcome when treating depression and anxiety disorders. More than half of the clinicians represented that they never used standardized measures to evaluate outcome. The most commonly used measures were BDI, Hospital Anxiety Depression Scale (HADS), ${ }^{36}$ HDRS. Recently, Zmimerman and McGlinchey ${ }^{7}$ also surveyed to determine how frequently psychiatrists used scales to measure outcome when treating depressed patients and, to ascertain the reasons for the lack of use for those clinicians who do not regularly use such scales. The majority of psychiatrists indicated that they never or rarely used scales to monitor outcome, and less than $10 \%$ almost always used scales to monitor outcome of depression treatment. The reasons for not routinely using scales in their clinical practice indicated because clinicians did not believe using scales would be helpful, the scales take too much time to use, and they were not trained in their use.

As above mentioned, there were used to be standardized in Korea for many depression rating scales developed in other countries, alike depression rating scales developed in Korea is using. However, little is systematic survey or study for what degree might be current use with mental health specialists working in clinical. Therefore, this study was to investigate the current use of depression measures in clinical setting in Korea. Namely the goals of the present study were to investigate the frequency and reason of not using, the degree of perceived satisfaction of currently available depression rating scales, and the perceived agreement between subjective clinical interviews and depressive measures. We hope this investigation is a basic research for inventing Korean standardized diagnosis and rating scales for depression in the future.

\section{METHODS}

\section{Subjects}

This study was conducted from July to September, 2006 and the questionnaire was distributed to psychiatrists and mental health clinical psychologists by mail. Participants in this study were psychiatrists working at university hospitals, general hospitals, mental hospitals, and private practices. Some psychiatrists involved in one of the national research projects for depression, 'Clinical Research Center for Depression.' Clinical psychologists were working at university hospitals, general hospitals, mental hospitals, mental health centers, counseling clinics, and research institutes. The questionnaires were distributed to totally 208 psychiatrists and 60 clinical psychologists by mail. 123 (59.1\%) of psychiatrists and 50 (83.3\%) of clinical psychologists were replied to our center. So, the total return rate was $64.9 \%$. Finally, 123 psychiatrists and 50 clinical psychologists were included in this study by excluding incomplete answers. Demographic data of the total subjects filling in the questionnaires were shown in Table 1.

\section{Questionnaire}

Working committee was organized and composed of four psychiatrists, two clinical psychologists and one medical statistician to make a draft of the questionnaire after reviewing depression rating scales used in Korea. This committee had several revisions of questionnaire for making an appropriate 
Table 1. Demographic data for all survey responders

\begin{tabular}{|c|c|c|c|c|}
\hline & & Psychiatrist & Clinical psychologist & All \\
\hline & & $\mathrm{N}(\%)$ & $\mathrm{N}(\%)$ & $\mathrm{N}(\%)$ \\
\hline \multirow[t]{2}{*}{ Sex } & Male & $107(87.0)$ & $17(34.0)$ & $124(71.7)$ \\
\hline & Female & $16(13.0)$ & $33(66.0)$ & $49(28.3)$ \\
\hline Age & & $42.0(8.9)$ & $31.9(6.7)$ & $39.1(9.5)$ \\
\hline \multirow[t]{3}{*}{ Working region } & Seoul, Gyeonggido & $16(13.0)$ & $9(18.0)$ & $25(14.4)$ \\
\hline & Daegu, Gyeongbuk & $85(69.1)$ & $39(78.0)$ & $124(71.3)$ \\
\hline & Jeollado & $22(17.9)$ & $2(4.0)$ & $24(13.8)$ \\
\hline \multirow[t]{6}{*}{ Working setting } & University hospital & $56(45.5)$ & $17(34.0)$ & $73(42.0)$ \\
\hline & General hospital & $17(13.8)$ & $3(6.0)$ & $20(11.5)$ \\
\hline & Mental hospital & $26(21.1)$ & $7(14.0)$ & $33(19.0)$ \\
\hline & Individual hospital & $22(17.9)$ & $4(8.0)$ & $26(14.9)$ \\
\hline & Centers and research institute & $0(0.0)$ & $15(30.0)$ & $15(8.6)$ \\
\hline & Other & $2(1.6)$ & $4(8.0)$ & $6(3.4)$ \\
\hline \multirow[t]{5}{*}{ Years after a license } & Under 5 years & $34(27.6)$ & $36(72.0)$ & $70(40.2)$ \\
\hline & Under 5-10 years & $32(26.0)$ & $10(20.0)$ & $42(24.1)$ \\
\hline & Under $10-15$ years & $18(14.6)$ & $3(6.0)$ & $21(12.1)$ \\
\hline & Under $15-20$ years & $12(9.8)$ & $1(2.0)$ & $13(7.5)$ \\
\hline & Over 20 years & $27(22.0)$ & $0(0.0)$ & $27(15.5)$ \\
\hline
\end{tabular}

question and amount of it through many meetings.

The questionnaire consisted of total 6 items. The first item of questionnaire elicited subjects' demographic characteristics (age, sex) and professional background (working region, working setting, years after a license). The second item of the questionnaire included 5 questions. The first question was "how often do you use depression rating scales for patients complainting of depressive symptoms" and "how often do you use depression rating scales for patients complainting of ones mainly other than those symptoms". The visual analog scores ranging from 0 to 100 percent was used to assess. The second question was "What do you do purpose using a rating scale?". This question was only checked in clinicians answered 'yes' (psychiatry 54.5\%, clinical psychologists $88 \%$ ), which use depression rating scales for patients. Subjects were asked to choose one of next six items; 1) screening 2) diagnosis 3) differentiated diagnosis 4) severity 5) determination of treatment effect and observation of symptom changes 6 ) other. The third question was "Why you do not use scales in clinical practice". Subjects were asked to choose one of next five items; 1) I can do sufficiently diagnosis and assessment by only psychiatric interview 2) I am not familiar with use of rating scales 3) I can't believe reliability and validity of rating scales 4 ) I don't want to be any more economic burden to patients 5) other. To next question, subjects were asked to check visual analog scale to assess the subjective degree of satisfaction after use of rating scales and the perceived level of agreement between subjective interview of psychiatrists and results of rating scale. The fifth item was "Please indicate three in order what do you do kinds of most frequently using rating scales among 25 domestic and foreign depression rating scales including standardized and non-standardized ones in Korea". If it is below $50 \%$, they were asked to directly describe why they do not use scales in clinical practice.

\section{Data analysis}

Data were analyzed with Statistical Package for the Social Sciences Win. Ver. 14.0 (SPSS Inc., Chicago, IL, USA) and significance level was 0.05 . Mean, standard deviation and independent $t$-test were used for quantitative data and frequency, percent and $\chi^{2}$-test were utilized for qualitative data.

\section{RESULTS}

\section{Current use of depression rating scales}

When a patient was examined medically with chief complaints of depression symptoms and other ones except depression, the frequency of using depression rating scales was significantly different between psychiatrists and clinical psychologists $(\mathrm{p}<0.001)$ and the average rate of clinical psychologists was higher than that of psychiatrists. Totally, in about $70 \%$ of cases with depression symptoms and around $44 \%$ of cases with other symptoms except depression, depression rating scales were used. A purpose of use to rating scales in med- 
ical examination of depression patients was investigated and there was no statistically significant difference between the two groups (Table 2).

Subjects who reported using below 50\% ware asked the reasons for not using scales in clinical practice. More than $60 \%$ of psychiatrists was indicated that they did sufficient diagnosis and assessment by only psychiatric interview, about $19.6 \%$ that did not familiar with use of rating scales, while $80 \%$ of clinical psychiatrists did other (Table 3).

\section{Agreement and satisfaction between subjective interviews and results of depression rating scales}

The perceived level of agreement between subjective interviews and results of depression rating scales was found to be about 70\% overall, psychiatrists and clinical psychologists did not show any significant difference in it (Table 4). For the cases in which the agreement was less than $50 \%$, reasons for that was analyzed qualitatively and answers such as 'results of the scales are exaggerated or underestimated compared to an actual condition', 'the scales focus on subjective symptoms', 'questions and expression of the scales are vague' and 'children do not recognize themselves well' were observed.

Overall, the subjective degree of satisfaction at depression rating scales was $67 \%$ and there was no significant difference between the two groups (Table 4). For the cases showing less than $50 \%$ satisfaction, reasons including 'various patterns of depression exist', 'there is difference between subjective complaints and results of an interview in medical examination, 'diagnostic usefulness is poor', 'severity is not reflected accurately' and 'patients refuse to answer some of questions (ex. sexual contents)' were pointed out.

\section{Kinds of use of depression rating scale}

Among currently used rating scales, the most commonly

Table 2. Rate and purpose of use of depression rating scales

\begin{tabular}{|c|c|c|c|c|}
\hline & Psychiatrist & Clinical psychologist & All & \multirow{2}{*}{$\mathrm{t}(\mathrm{p})$} \\
\hline & & Mean (SD) & & \\
\hline \multicolumn{5}{|l|}{ Rate of use } \\
\hline Patient complainting of depressive symptoms & $59.96(28.50)$ & $84.77(24.78)$ & $69.79(29.60)$ & $-4.72(0.000)$ \\
\hline Patient complainting of mainly other than depressive symptoms & $32.78(25.75)$ & $62.05(31.74)$ & $44.38(31.60)$ & $-5.34(0.000)$ \\
\hline Purpose of use & & $\mathrm{N}(\%)$ & & $\chi^{2}(p)$ \\
\hline Screening & $13(19.4)$ & $14(31.8)$ & $27(24.3)$ & \multirow{6}{*}{$9.94(0.077)$} \\
\hline Diagnosis & $8(11.9)$ & $10(22.7)$ & $18(16.2)$ & \\
\hline Differentiated diagnosis & $2(3.0)$ & $1(2.3)$ & $3(2.7)$ & \\
\hline Severity & $25(37.3)$ & $16(36.4)$ & $41(36.9)$ & \\
\hline Treatment effect judgement and processing observation & $18(26.9)$ & $3(6.8)$ & $21(18.9)$ & \\
\hline Other & $1(1.5)$ & $0(0.0)$ & $1(0.9)$ & \\
\hline
\end{tabular}

SD: standard deviation

Table 3. Reason for not using depression rating scales

\begin{tabular}{|c|c|c|c|c|}
\hline & Psychiatrist & Clinical psychologist & All & \multirow{2}{*}{$\chi^{2}(\mathrm{p})$} \\
\hline & \multicolumn{3}{|c|}{$\mathrm{N}(\%)$} & \\
\hline I can do sufficiently diagnosis and assessment in only psychiatric interview & $38(67.9)$ & $1(20.0)$ & $39(63.9)$ & \\
\hline I am not familiar with use of rating scales & $11(19.6)$ & $0(0.0)$ & $11(18.0)$ & \\
\hline I can't believe reliability and validity of rating scales & $3(5.4)$ & $0(0.0)$ & $3(4.9)$ & $30.33(0.000)$ \\
\hline I don't want to be any more economic burden to patients & $2(3.6)$ & $0(0.0)$ & $2(3.3)$ & \\
\hline Other & $2(3.6)$ & $4(80.0)$ & $6(9.8)$ & \\
\hline
\end{tabular}

Table 4. Agreement rate between interview and the results of rating scale for depressive patients, a general satisfaction after use of depression rating scales

\begin{tabular}{cccc}
\hline & Psychiatrist & Clinical psychologist & All \\
\cline { 2 - 3 } & & Mean (SD) & \\
\hline Agreement & $71.68(12.93)$ & $69.71(20.79)$ & $70.89(16.45)$ \\
Satisfaction & $68.35(13.84)$ & $65.57(16.32)$ & $67.26(14.85)$ \\
\hline
\end{tabular}

SD: standard deviation 
used scales for depression patients was BDI (68.9\%), HRSD (30.5\%) and SCL-90-R (18.9\%) in the order for psychiatrists while BDI (57.4\%) was most frequently used, followed by MMPI (37.0\%) and SCL-90-R (31.1\%) for clinical psychologists. Psychiatrists and clinical psychologists showed a significant difference in the first and the second ranks $(\mathrm{p}<0.001)$ but there was no significant difference in the third rank. Both of the two groups responded that reasons for not using scales not ranking the first, the second and the third were unfamiliarity, unsecured reliability and validity, lack of information on them and a long time for scoring them.

\section{DISCUSSION}

With psychiatrists and clinical psychologists working at the clinical field as subjects this study surveyed frequency of use, depression measures, the subjective degree of satisfaction and the perceived level of agreement between subjective clinicians judgment and rating scales. Such a study was performed first in the domestic clinical field and it was considered to be a basic research for development of Korean standardized depression diagnosis and rating scales in future.

Similar to the results of the survey conducted by Gilbody et al., ${ }^{22}$ Zimmerman and McGlinchey, ${ }^{7}$ our results indicated that psychiatrists are not using depression rating sales to evaluate patients complainting of depressive symptoms. Also, our results showed that the clinical use of depression rating scales is more frequent in the clinical psychologists than in that of psychiatrists regardless of whether depressive symptoms or not. This result could be considered to reflect that two groups are clearly different in professional role in clinical practices. Although clinical psychologist's main work is to assessing patients, it is remarkable that most psychiatrists are not generally using quantified measures to evaluate outcome when treating depression patients. To those, foreign studies suggested that psychiatrists did not believe that the regular use of scales would be clinically helpful, and that scales would take too much time to administer and they have a lack of previous training. ${ }^{7}$ Similarly, our surveys indicated that they were able to diagnosis and assessment by only subjective psychiatric interview and that did not familiar with use of rating scales. Like Zimmerman and McGlinchey, ${ }^{7}$ we suspect that psychiatrists were considering clinician rating scales such as the Hamilton Rating Scale for Depression ${ }^{21}$ when answering why they did not use scales and were not believing depression rating scales to be reliable, valid measures. As the most helpful advantages of the depression rating scales both of psychiatrists and clinical psychologists pointed out rating of severity and screening, so one of main purposes of the scales could be said to be screening. As results of self-rated inventories such as $\mathrm{BDI}^{9}$ and those of a structured interview like Schedule for Affective Disorders and Schizophrenia ${ }^{23}$ were found to be similar to a certain degree, the depression rating scales such as BDI have been used widely as a method to screen a group with high possibility of depression. ${ }^{10,23-25}$ Also, there were the advantage of self-report questionnaires, which require little training and do not take much clinician time to administer and score.

Among domestic and foreign depression rating scales including standardized and non-standardized ones in Korea, the types of depression rating scales currently used in clinical practices field were observed not to be various. Psychiatrists used frequently BDI, HRSD and SCL-90-R in the order and clinical psychologists did BDI, MMPI and SCL-90-R in the order. Similar to results of the survey of psychiatrists practising conducted in the UK by Gilbody et al. ${ }^{22}$ indicated that the most commonly used measures were BDI, HADS, HRSD for identifying and assessing the severity and measuring clinical change over time of depression and anxiety problems. As above mentioned depression rating scales such as BDI, HRSD, SCL-90-R, MMPI have been known as proper scales from determining severity of symptoms to diagnosing the possibility of depression and to observing the degree of improvement after treatments. ${ }^{6-10,23-25}$ The types of scales could different according to what is measured, also there were a advantage and a shortcoming in each scales. Namely there were the advantage of self-rating scales, which require little training and do not take much clinician time to administer and score, but there were not used to diagnosis depression. However, the clinician rating scales such as HRSD had the shortcoming in aspect of time and cost as administer systematically training clinicians, but was able to assess more objectively and exactly symptoms and severity. ${ }^{10.23-25}$ Also, we suspect that the difference between the two groups was considered to result from acquaintance with only these scales during the training period of psychiatrists and clinical psychologists. Moreover, although total 25 depression rating scales including standardized and non-standardized ones were presented, both of the two groups chose only several scales as currently used ones. Both of the two groups responded that reasons for not using scales not ranking the first, the second and the third were unfamiliarity, unsecured reliability and validity, lack of information on them and a long time for scoring them. These results were similar with those of Gilbody et al. ${ }^{22}$ and Zimmerman and McGlinchey. ${ }^{7}$ reporting that the use of previous scales were avoided because their reliability and validity were doubted, an economic burden was much and using them usually every time was annoying. To deal with these problems simple scales with a small number of questions which validity and reliability were already proven were developed and used and they included Clinically Useful Depression 
Outcome Scale (CUDOS), ${ }^{26}$ The 16-item Quick Inventory of Depressive Symptomatology, ${ }^{27}$ Patient Health Questionnaire-2 (PHQ-2) $)^{28,29}$ and PHQ-9. ${ }^{14}$ Among them validity and reliability of CUDOS $^{33}$ were verified and PHQ- ${ }^{34}$ were in the process of being verified. In addition, a study on validity and reliability of Psychiatric Diagnostic Screening Questionnaire, ${ }^{30}$ which is a self-rated inventory meeting DSM-IV ${ }^{35}$ diagnosis standards and can be utilized usefully, was also being conducted and it was expected to be a very useful scale in outpatient clinics considering the environment of Korean clinical field in which doctors should examine many patients for a short time.

The perceived level of agreement between results of depression rating scales and those of subjective clinical interviews, the degree of satisfaction after using the scales were no significant difference between the two groups. And they were tended to be high by recording about $70 \%$ in the two groups. However, subjects answering that the level of agreement was less than $50 \%$ were pointed out exaggerated or underestimated rating, subjective complaints, vague questions and expression and limitation for specific subjects (ex. children) as the reasons for lower agreement. These responses reflected limitations of self-rated inventories well and many researchers had referred to them..$^{27}$ In other words, although self-rated inventories were widely used as one of the most general methods among psychological measurements, their results could be affected by a tendency of showing a socially desirable attitude and they could obtain unreliable data from young children at a cognitively premature development stage. In addition, reasons for less than $50 \%$ of satisfaction at the scales were reported to be diversity of depression patterns, disagreement among results of tests, inaccuracy of severity rating and no response, and they presented limitations of previous scales well. Like the result of survey, it was alike those of previous researches saying that children also showed depression including emotional, cognitive, motive, physical and psycho-motor symptoms like adults and specific clinical characteristics could be found according to ages. ${ }^{31,32}$ Therefore, this result suggested again urgency of development of scales screening well various clinical patterns of basically special groups and reflecting cultural characteristics and values.

In conclusion, as the rate of use of depression rating scales of clinical psychologists was higher than that of psychiatrists, difference in roles of the two groups could be observed clearly. In addition, currently used depression rating scales at the clinical field were not various. While agreement and satisfaction were found to be positive overall among the subjects of this study, subjects avoiding using them actually showed a negative response. The reasons for the negative evaluation were various clinical patterns according to gender and age, prob- lems related to reliability and validity of the scales, specialty according to development stages, unfamiliarity and lack of information on them, and they reflected problems of existing scales. This result is thought to exaggerate necessity of development of depression rating scales more, and development of scale handling with problems of existing scales and being useful for a limited environment of outpatient clinics where doctors should see many patients for a short time may urgent. However, some scales supplementing the limitations of existing scales mentioned above were already developed, verified and used for academic and clinical purposes. Among them several ones' validity and reliability were also proven in Korea. Like this, the reason why they were already invented but were not widely used was considered to be lack of education and advertisement for them. Rather than only trying to invent domestic rating scales, standardization of scales developed and verified in foreign countries also should be considered to secure variety and usefulness of depression rating scales.

Lastly, this study had following limitations. This study recruited subjects only working at the clinical field. But, if subjects of this study had included ones with licenses not working at the field to reflect their opinion, a more accurate survey on current situation would have been possible because there may be a difference between kinds and purpose of use of scales demanding at nonclinical practice and clinical one. In addition, the subjects were not various according to regions because a considerable data was lost in the process of sending and collecting questionnaires by mail and clinical psychologists in other regions except the region of researchers were hard to be recruited. That showed indirectly that there was deviation in distribution of them according to regions and their number was also limited.

\section{Acknowledgments}

This study was supported by a grant of the Korean Health 21 R \& D Project, Ministry of Health and Welfare, Republic of Korea (A050047).

\section{REFERENCES}

1. Korean Neuropsychiatry Association. Textbook of Neuropsychiatry 2nd edition. Seoul: Joongang; 2005.

2. Murray CJ, Lopez AD. Evidence-based health policy--lessons from the Global Burden of Disease Study. Science 1996;274:740-743.

3. Weissman MM, Bland RC, Canino GJ, Faravelli C, Greenwald S, Hwu HG, et al. Cross-national epidemiology of major depression and bipolar disorder. JAMA 1996;276:293-299.

4. Cho MJ, Chang SM, Hahm BJ, Chung IW, Bae A, Lee YM, et al. Prevalence and correlates of major mental disorders among Korean adults: a 2006 national eipdemiologic survey. J Korean Neuropsychiatr Assoc 2009;48:143-152.

5. Chang SM, Shon JH, Lee JY, Choi JH, Cho SJ, Jeon HJ, et al. Charateristics of diagnostic criteria for depression in Korea. J Korean Neuropsychiatr Assoc 2007;46:447-452.

6. Yang JK. The Self-rating depression scale on psychiatric patients. J Korean Neuropsychiatr Assoc 1982;21:217-227. 
7. Zimmerman M, McGlinchey JB. Why don't psychiatrists use scales to measure outcome when treating depressed patients? J Clin Psychiatry 2008;69:1916-1919.

8. Dew MA, Switzer GE, Myaskovsky L, Dimartini AF, Tovtkorshynska MI. Rating Scale for mood disorders, in Textbook. In: Stein DJ, Kupfer DJ, Schatzberg AF, editors. The American psychiatric publishing textbook of mood disorders (1st ed). Arlington, VA: American Psychiatric Publishing Inc, 2006, p.69-97.

9. Lee YH, Song JY. A study of the reliability and the validity of the BDI, SDS and MMPI-D scales. Korean J Clin Psychol 1991;10:98-113.

10. Sung HM, Kim JB, Park YN, Bai DS, Lee SH, Ahn HY. A study on the reliability and the validity of Korean version of the Beck Depression Inventory-II (BDI-II). J Korean Soc Biol Ther Psychiatry 2008;14:201-210.

11. Zung WW. A self-rating depression scale. Arch Gen Psychiatry 1965; 12:63-70.

12. Hathaway S, Mckinley C. Minesota multiphasic personality inventory. New York: Psychological corporation; 1952.

13. Derogatis L. The SCL-90-R Manual. Baltimore, MD: Clinical Psychometric Research Unit. Johns Hopkins University School of Medicine; 1977.

14. Koenke K, Spitzer RL, Williams JB. The PHQ-9: validity of a brief depression severity measure. J Gen Intern Med 2001;16:606-613.

15. Yesavage JA, Brink TL, Rose TL, Lum O, Huang V, Adey M, et al. Development and validation of geriatric depression screening scale: a preliminary report. J Psychol Res 1983;17:37-49.

16. Cho MJ, Bae JN, Suh GH, Hahm BJ, Kim JK, Lee DW, et al. Validation of Geriatric Depression Scale, Korean version (GDS) in the assessment of DSM-III-R major depression. J Korean Neuropsychiatr Assoc 1999; 38:48-63.

17. Kovacs M. The children's depression inventory: a self-rated depression scale for school-aged youngsters. Unpublished Manuscript: University of Pittsburgh; 1983.

18. Cho SC, Lee YS. Development of the Korean form of the Kovacs' Children's Depression Inventory. J Korean Neuropsychiatr Assoc 1990;29: 943-956.

19. Lee MS, Rhee MK. A development of Korea depression scale. J Korean Neuropsychiatr Assoc 2003;42:492-506.

20. Department of Health. A national service framework for mental health. London: Department of Health; 1999.

21. Hamilton M. A rating scale for depression. J Neurol Neurosurg Psychiatry 1960;23:56-62.
22. Gilbody SM, House AO, Sheldon TA. Psychiatrists in the UK do not use outcomes measures. National survey. Br J Psychiatry 2002;180:101103.

23. Endicott J, Spitzer RL. A diagnostic Interview: the schedule for affective disorders and schizophrenia. Arch Gen Psychiatry 1978;35:837-844.

24. Vredenburg K, Flett GL, Krames L. Analogue versus clinical depression: a critical reappraisal. Psychol Bull 1993;113:327-344.

25. Oh KJ, Kim EJ, Ha EH. Psychosocial characteristics of women with clinical and subclinical depression. Korean J Clin Psychol 1999;18:95104.

26. Zimmerman M, Chelminski I, McGlinchey JB, Posternak MA. A clinically useful depression outcome scale. Compr Psychiatry 2008;49:131140.

27. Rush AJ, Trivedi MH, Ibrahim HM, Carmody TJ, Arnow B, Klein DN, et al. The 16-Item Quick Inventory of Depressive Symptomatology (QIDS), clinician rating (QIDS-C), and self-report (QIDS-SR): a psychometric evaluation in patients with chronic major depression. Biol Psychiatry 2003;54:573-583.

28. Löwe B, Kroenke K, Gräfe K. Detecting and monitoring depression with a two-item qestionnaire (PHQ-2). J Psychosom Res 2005;58:163-171.

29. Kroenke K, Spitzer RL, Williams JB. The Patient Health Questionnaire-2: validity of a two-item depression screener. Med Care 2003;41:1284-1292.

30. Zimmerman M, Mattia JI. The reliability and validity of a screening Questionnaire for 13 DSM-IV Axis I disorders (the Psychiatric Diagnostic Screening Questionnaire) in psychiatric outpatients. J Clin Psychiatry 1999;60:677-683.

31. Shin MS, Kim MK. Assessment of childhood depression. Korean J Child \& Adol Psychiatr 1994;5:12-27.

32. Carlson GA, Garber J. Developmental Issues in the Classification of Depression in Children. In: Rutter M, Izard CE, Read PB, editors. Depression in Young People: Developmental and Clinical Perspective. New York: Guilford Press; 1986.

33. Nam WH, Park YN, Kim HC, Jung SW, Chae SS, Suh YL, et al. The reliability and validity of Korean version of clinically useful depression outcome scale. J of Kor Soc Dep and Bip Disorders 2008;6:120-128.

34. Lim KH, Park YN, Kim DH, Shin IH, Lee WS, Kim JB. A Preliminary Study of the Standardization of the Korean Version of the Patient Health Questionnaire-9. Korean J Health Promot Dis Prev 2009;9:275-280.

35. American Psychiatric Association. Diagnostic and Statistical Manual of Mental Disorders, 4th Edition, Text Revision. Washington DC: American Psychiatry Association; 2000. 